\title{
BMJ A prospective cohort study of the Open changing mental health needs of adolescents in custody
}

\author{
Charlotte Lennox, ${ }^{1}$ Vicky Bell, ${ }^{1}$ Kate O'Malley, ${ }^{2}$ Jenny Shaw, ${ }^{1}$ Mairead Dolan ${ }^{3}$
}

To cite: Lennox C, Bell V, O'Malley $\mathrm{K}$, et al. A prospective cohort study of the changing mental health needs of adolescents in custody. BMJ Open 2013;3: e002358. doi:10.1136/ bmjopen-2012-002358

- Prepublication history for this paper are available online. To view these files please visit the journal online (http://dx.doi.org/10.1136/ bmjopen-2012-002358).

Received 21 November 2012 Revised 12 February 2013 Accepted 15 February 2013

This final article is available for use under the terms of the Creative Commons Attribution Non-Commercial 2.0 Licence; see http://bmjopen.bmj.com

${ }^{1}$ Manchester Academic Health Science Centre, The University of Manchester, Manchester, UK

${ }^{2}$ University of Ballarat, Ballarat, Victoria, Australia ${ }^{3}$ Centre for Forensic Behavioural Science, Monash University, and the Victorian Institute of Forensic Mental Health, Melbourne, Victoria, Australia

Correspondence to Dr Charlotte Lennox; charlotte.lennox@ manchester.ac.uk

\section{ABSTRACT}

Objective: To investigate changes in mental health and other needs, as well as clinical and diagnostic 'caseness', in a sample of adolescents over a 6-month period following entry into a Young Offenders Institution in the UK.

Design: Prospective cohort study.

Setting: One Young Offenders Institution between November 2006 and August 2009.

Participants: 219 male adolescents aged $15-18$ years $(M=16.56 ; S D=0.6)$ were assessed at baseline (median=4; range $0-26$ days following reception into custody) on the Salford Needs Assessment Schedule for Adolescents (SNASA) and Kiddie Schedule for Affective Disorders and Schizophrenia (K-SADS). Participants were then reassessed at 3-month and 6-month postbaseline to document any change in mental health.

Results: Of the initial baseline sample, 132 were still in the study at 3-month postbaseline and 63 were still available for assessment at 6 months. There were no differences between those who were not available for assessment at the three key stages in terms of demographic and criminological data. Over time there was a general improvement in mental health. While the proportion of participants with a mental health need (SNASA) did not change over time, symptom severity as measured by the SNASA did reduce significantly. When we assessed diagnostic 'caseness' using the K-SADS, three young people showed significant mental health deterioration.

Conclusions: In line with previous studies, we found that symptoms in prison generally improved over time. Prison may provide an opportunity for young people previously leading chaotic lifestyles to settle into a stable routine and engage with services; however, it is unclear if these would be maintained either within the prison or on release into the community.

\section{INTRODUCTION}

There are several reports from the $\mathrm{UK}^{1-4}$ and internationally ${ }^{5-8}$ that suggest higher levels of mental health problems in adolescents ( $<18$ years) in custodial settings compared with the general population of

\section{ARTICLE SUMMARY}

Article focus

- We examined changes in mental health and other needs across three time points.

- We predicted on the basis of previous research that many needs would be met following incarceration and that 'caseness' would decrease over time for the majority of adolescents who remained in custody over the study period.

Key messages

- We found high levels of mental health need of adolescents on reception into prison.

- Mental health improves over the first 6 months of imprisonment.

Strengths and limitations of this study

- We used a prospective cohort of adolescents on reception into prison.

- There have been no previous studies on changes in mental health needs and psychiatric morbidity in adolescents (15-18 years).

- We assessed needs as well as psychiatric morbidity.

- There was high attrition between baseline and 6-month follow-up as many adolescents were discharged (released or transferred), often with little warning.

- We did not examine what interventions the young people had that may have impacted on the reduction in their needs over time.

adolescents. Despite recent improvements in prison healthcare, the mental health needs of adolescents often remain unmet and the prognosis for this group is poor. ${ }^{9}$

Detention in custody separates a young person from their normal support networks and places them in an environment where they may be exposed to stress, boredom and bullying. ${ }^{10}$ This can exacerbate mental health symptoms and increase the risk of suicidal behaviour. ${ }^{11}$ Since 1995 in the UK, there have been 19 self-inflected deaths of adolescents in custody, ${ }^{12}$ and studies suggest that suicide tends to occur early in the 
detention period. ${ }^{13}$ Factors associated with suicide in custody include substance misuse, mental illness and a previous history of self-harm. ${ }^{13} 14$ These factors are all common among offender populations. ${ }^{15} 16$ According to Liebling ${ }^{17} 18$ there are three distinct groups of prisoners vulnerable to suicide: life sentence prisoners, the psychiatrically ill and 'poor copers'. Poor copers account for the largest proportion of suicides, tend to be younger and have difficulty adjusting to aspects of prison life such as isolation from family and friends, dealing with other prisoners, boredom and a lack of constructive activity.

Historically, studies that have investigated mental disorders in young people have relied on psychiatric diagnosis tools, many of which were developed for use with an adult population. ${ }^{1}$ It has been argued, however, that while knowledge of the prevalence of specific psychiatric disorders is useful on one level, it does not necessarily assist with the planning of health services for young people as this can be influenced by a number of factors, including the availability of an effective intervention and a willingness to accept it. ${ }^{19}$ A needs assessment approach is thought to be a useful additional model for meaningful measurement of health problems and service provision. ${ }^{2}{ }^{20}$ There is a recognition that needs change so a longitudinal approach is required to investigate changes in mental health need following admission to custody. ${ }^{2}$

There is a small, but growing, body of research looking at the course of mental health problems following detention in custody in adults and adolescents ${ }^{21-23}$ The latter study suggests that mental health symptoms improve over time, but remain higher than the general population, and for a few individuals symptoms deteriorate. Most of these studies have been conducted in adult samples and there are relatively little data looking at changes in mental health problems in adolescents in custody over time. A UK study ${ }^{2}$ did assess changes in mental health needs and psychiatric morbidity in children and adolescents (10-17 years) entering Secure Children's Homes (custodial setting within the care system, managed by the local authority) and then at 3-month follow-up. While they found a reduction in mental health, social and educational needs following admission (particularly aggression, substance misuse, relationships and education), they also noted an increase in needs relating to depression, anxiety problems and Post Traumatic Stress Disorder (PTSD) symptoms.

There have been no similar studies on changes in mental health needs and psychiatric morbidity in adolescents (15-18 years) admitted to Young Offender Institutions (YOI's; custody setting managed by Her Majesties Prison Service). Given the recent reports that almost $50 \%$ of male adolescents with mental health problems were missed at reception screening in a YOI, ${ }^{4}$ and the concern over the risk of suicide in those with undetected psychiatric morbidity or mental health needs, more work is needed to assess the impact of being in prison on adolescents' mental health needs.
This study examined changes in mental health and other needs across three time points from baseline, (median $=4$; range 0-26 days following reception into custody), 3-month postbaseline, and 6-month postbaseline. We used a well-validated needs assessment tool and a standardised measure of psychiatric morbidity to assess changes in the sampled cohorts at each time period.

We predicted on the basis of previous research ${ }^{2}$ that mental health and other needs, as assessed by the Salford Needs Assessment Schedule for Adolescents $\left(\mathrm{SNASA}^{24}\right)$, would decrease over time and that diagnostic 'casesness', as assessed by the Kiddie Schedule for Affective Disorders and Schizophrenia $\left(\mathrm{K}_{-} \mathrm{SADS}^{25}\right)$, would decrease over time.

\section{METHOD}

\section{Procedure}

The study was approved by the South Staffordshire Research Ethic Committee and the work was conducted between November 2006 and August 2009. A consecutive sample of adolescent offenders (aged 15-18 years) from one YOI was taken from the list of new prison receptions each day. Participants were informed about the study within 3 days of reception. Written informed consent was obtained from all participants. For those aged under 16 years, parental/carer consent was obtained. Those who were sentenced to greater than 6 months and those who were on remand for a serious offence which was likely to result in greater than a 6-month sentence were approached and invited to participate in the study. A total of 296 participants were approached and 275 consented to undergo baseline, 3-month and 6-month follow-up assessments. A total of 219 actually completed baseline interviews which were conducted at the mental health day unit. All participants were seen individually over 2-3 $1 \mathrm{~h}$ sessions to complete the assessments. Researchers administering the assessment schedules had training provided by accredited trainers.

\section{Assessments}

\section{Salford Needs Assessment Schedule for Adolescents}

The SNASA $^{25}$ is a structured interview specifically designed to assess the psychosocial needs of adolescents with mental health or conduct problems. The SNASA covers five domain areas: relationships (peer/social and family relationships), education (attendance, performance and weekday occupation), violent behaviour (destructive and hostile), risky behaviour (substance and alcohol misuse, and inappropriate sexual behaviour) and mental health (depressed mood, deliberate selfharm, anxiety symptoms, PTSD problems, hallucinations, delusions, paranoid beliefs and hyperactivity). For each need, the interview gathers lifetime information on symptom severity (five-point scale). A threshold of two (moderate problem) was used for identifying an area of need. Any area of need in a domain became a 'case'. The SNASA was chosen as it has been used in previous 
studies in adolescent offenders. ${ }^{2} 4$ The SNASA has excellent psychometric properties with inter-rater and test-retest reliability $\kappa$ coefficients ranging from 0.73 to $0.85 .^{24}$ The SNASA also uses an algorithm that can be used to factor in other scores such as subjective rating of problem severity, motivation to change and carer distress. Owing to difficulties in obtaining carer information for all the young people, the algorithm was not used in this study.

\section{Kiddie Schedule for Affective Disorders and Schizophrenia}

The K-SADS ${ }^{25}$ is a semistructured diagnostic interview designed to assess current and past episodes of psychopathology in children and adolescents according to DSM-IV criteria. As the K-SADS was used for research, it was administered by interviewing the participant only. The Screen Interview focuses on the primary symptoms for each diagnosis in the K-SADS. This study focuses on current diagnoses. Specific probes and scoring criteria are provided to assess each symptom. The participant was asked if they have 'ever' experienced the symptom. If the answer was no, then the symptom was rated as negative for current episodes and then proceeded to the next question. If the answer was yes, the probes were used to establish more information and to access against the scoring criteria. If the scoring criteria were met, then the diagnostic supplement was completed. There are six Diagnostic Supplements included with the K-SADS: affective disorders, psychotic disorders, anxiety disorders, behavioural disorders, substance abuse and other disorders. Each supplement has a list of symptoms, probes and criteria to assess current disorder. Criteria required for making DSM-IV diagnoses are provided. The K-SADS has excellent psychometric properties (ie, $\kappa$ 's between 0.63 and 0.85 for all diagnoses) ${ }^{25}$

\section{Statistical analysis}

Data were analysed using SPSS V.19. Group differences between participants retained and not retained in the study were assessed using $\mathrm{t}$ test or $\chi^{2}$ analysis. Repeated measures analysis of variance (ANOVA) was used to examine changes over the three time periods for those remaining in the study, but descriptive statistics are provided for all stages where data are available. As data were not always normally distributed, non-parametric statistics were used (Friedman test).

In an analysis of 'caseness', data were extracted from the K-SADS and SNASA to derive a sample that was clinically vulnerable shortly after reception. On the SNASA, 'caseness' at baseline was based on $>2$ scores from the SNASA mental illness domain. On the K-SADS, 'caseness' was determined by diagnostic cut-offs on the following key domains: psychosis, depression, PTSD, ADHD and anxiety disorders. For 63 young people, we were able to examine changes in 'caseness' over the three time periods.

\section{RESULTS}

Figure 1 shows participant flow through the study. A total of 219 young people gave informed consent and were assessed at baseline. All were adolescent boys with a mean age of 16.6 ( $\mathrm{SD}=0.6$; range $15-18$ ) years. The majority $(\mathrm{n}=186 ; 85 \%)$ described themselves as Caucasian, 12 $(6 \%)$ as Afro-Caribbean, $12(6 \%)$ as Asian and $9(4 \%)$ described themselves as from other ethnic backgrounds. Half of the sample were sentenced $(n=110)$ and 109 were on remand awaiting trial. For $133(61 \%)$ participants, this was their first time in prison. The mean sentence length for the 110 sentenced participants was 18.2 months $(\mathrm{SD}=11)$. The majority of offenders were incarcerated for violent offences $(72 \%)$. At the 3-month postbaseline assessment, there were 132 participants and at 6 -month postbaseline assessment there were 63 participants. There were no significant differences in the demographic and criminological profiles of those retained or not retained across the time points (see table 1).

\section{Changes in mental health and other needs}

The proportion of participants with a need in each SNASA domain across time periods is shown in figure 2. At baseline, the highest level of need was in the domain of education, followed by risky and violent behaviour. Mental health needs were identified in $43 \%$ of participants. Over time there was notable attrition in the sample, with only 63 cases remaining in the study by 6-month follow-up. Repeated measures ANOVA on the 63 cases indicated significant reductions in the proportion of participants with a need across all three time points for education $(\mathrm{F}=53.69$, df 2, 124, $\mathrm{p}=0.001)$, relationships $(\mathrm{F}=19.4$, df $2,63, \mathrm{p}=0.001)$ and risky

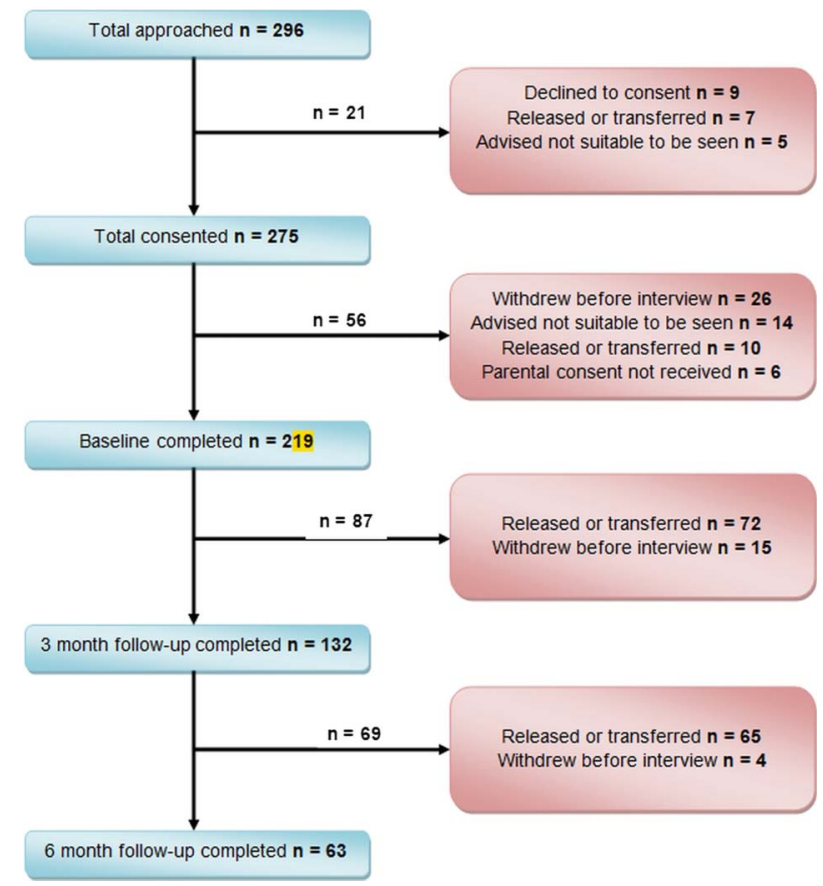

Figure 1 Participant dropout. 
Table 1 Demographics, criminological factors and mental health for participants retained and not retained in the study

\begin{tabular}{|c|c|c|c|c|c|c|c|c|}
\hline & \multicolumn{2}{|c|}{ Retained 3 months } & \multirow[b]{2}{*}{ Statistic } & \multirow[b]{2}{*}{ Significance } & \multicolumn{2}{|c|}{ Retained 6 months } & \multirow[b]{2}{*}{ Statistic } & \multirow[b]{2}{*}{ Significance } \\
\hline & Yes $n=132$ & No $n=87$ & & & Yes $n=63$ & No $n=69$ & & \\
\hline Age (mean) & $16.5(0.57)$ & $16.5(0.67)$ & $\mathrm{t}=0.23$ & 0.81 & $16.5(0.56)$ & $16.6(0.56)$ & -1.47 & 0.14 \\
\hline \multicolumn{9}{|l|}{ Ethnicity } \\
\hline White & $113(86 \%)$ & $73(84 \%)$ & \multirow[t]{2}{*}{$F=0.11$} & \multirow[t]{2}{*}{0.73} & $52(83 \%)$ & $61(88 \%)$ & \multirow[t]{2}{*}{$\mathrm{F}=0.92$} & \multirow[t]{2}{*}{0.34} \\
\hline Other & $19(14 \%)$ & $14(16 \%)$ & & & $11(17 \%)$ & $8(11 \%)$ & & \\
\hline \multicolumn{9}{|c|}{ Previous imprisonment } \\
\hline Yes & $49(37 \%)$ & $37(42 \%)$ & \multirow[t]{2}{*}{$F=0.64$} & \multirow[t]{2}{*}{0.42} & $24(38 \%)$ & $25(36 \%)$ & \multirow[t]{2}{*}{$F=0.04$} & \multirow[t]{2}{*}{0.82} \\
\hline No & $83(63 \%)$ & $50(56 \%)$ & & & $39(62 \%)$ & $44(64 \%)$ & & \\
\hline \multicolumn{9}{|l|}{ Prison status } \\
\hline Sentenced & $71(54 \%)$ & $39(45 \%)$ & \multirow[t]{2}{*}{$F=1.68$} & \multirow[t]{2}{*}{0.19} & $37(59 \%)$ & $35(51 \%)$ & \multirow[t]{2}{*}{$F=0.54$} & \multirow[t]{2}{*}{0.46} \\
\hline Remand & $61(46 \%)$ & $48(55 \%)$ & & & $26(41 \%)$ & $34(49 \%)$ & & \\
\hline \multicolumn{9}{|c|}{ Mental health need } \\
\hline Yes & $57(43 \%)$ & $36(41 \%)$ & \multirow[t]{2}{*}{$F=1.56$} & \multirow[t]{2}{*}{0.49} & $29(46 \%)$ & $28(41 \%)$ & \multirow[t]{2}{*}{$F=0.39$} & \multirow[t]{2}{*}{0.52} \\
\hline No & $75(57 \%)$ & $51(59 \%)$ & & & $34(54 \%)$ & $41(59 \%)$ & & \\
\hline
\end{tabular}

behaviour $(\mathrm{F}=80.04$, df 2,63, $\mathrm{p}=0.001)$; but no significant reductions for mental health $(\mathrm{F}=5.47$, df 2,63, $\mathrm{p}=0.06$ ) or violent behaviour $(\mathrm{F}=2.7$, df 2,63, $\mathrm{p}=0.25)$.

Table 2 shows the descriptive statistics for the total number of needs across domains. There were significant reductions in the number of needs in all domains over time. In the mental health domain, there were significant reductions in symptom severity for depressed mood ( $\mathrm{F}=18.41$, df 2,63, $\mathrm{p}=0.001)$, self-harm $(\mathrm{F}=25.1$, df 2,63, $\mathrm{p}=0.001)$, anxiety $(\mathrm{F}=18.6$, df $2,63, \mathrm{p}=0.001)$, psychotic symptoms $(\mathrm{F}=9.29$, df 2,63, $\mathrm{p}=0.01)$, a trend towards a reduction in PTSD symptoms $(\mathrm{F}=5.45$, df 2,63, $\mathrm{p}=0.06)$ over time, but no significant reduction in ADHD symptoms.

\section{Changes in psychiatric morbidity}

At baseline, the K-SADS identified 171 (78\%) with alcohol misuse, $159(73 \%)$ with substance misuse, 15 (7\%) with depression, 9 (4\%) with PTSD, 7 (3\%) with anxiety disorders and $4(2 \%)$ with psychosis. None of the participants had a diagnosis of mania. At 3 months $(\mathrm{n}=132)$, the K-SADS identified six $(5 \%)$ participants with depression, two $(2 \%)$ psychosis, two $(2 \%)$ with anxiety disorders and one (1\%) with PTSD. None of the participants had a diagnosis of mania, alcohol and/or substance misuse. At 6 months $(\mathrm{n}=63)$, the K-SADS identified two $(3 \%)$ with depression and one $(2 \%)$ with psychosis. None of the participants had a diagnosis of anxiety, mania, PTSD and alcohol and/or substance misuse.

\section{How does time spent in prison impact on mental} health-related clinical caseness?

Clinical 'caseness' at baseline was based on need symptom severity from the SNASA mental illness domain, and diagnostic cut-offs on the K-SADS (psychosis, depression, PTSD, ADHD and anxiety disorders). Figure 3 shows the participants assessed as being a case at each stage of the study. Of the 29 assessed as a case on the SNASA at baseline, 13 were still assessed as being a case at 6 months. Of the 15 assessed as a case on the K-SADS at baseline, two were still a case at 6-month follow-up. By contrast, of the 34 not deemed a case on the SNASA at baseline, six had emerged as new cases by 6-month follow-up. On the K-SADS, 59 were not
Figure 2 Proportion of participants with a need in each Salford Needs Assessment Schedule for Adolescents domain.

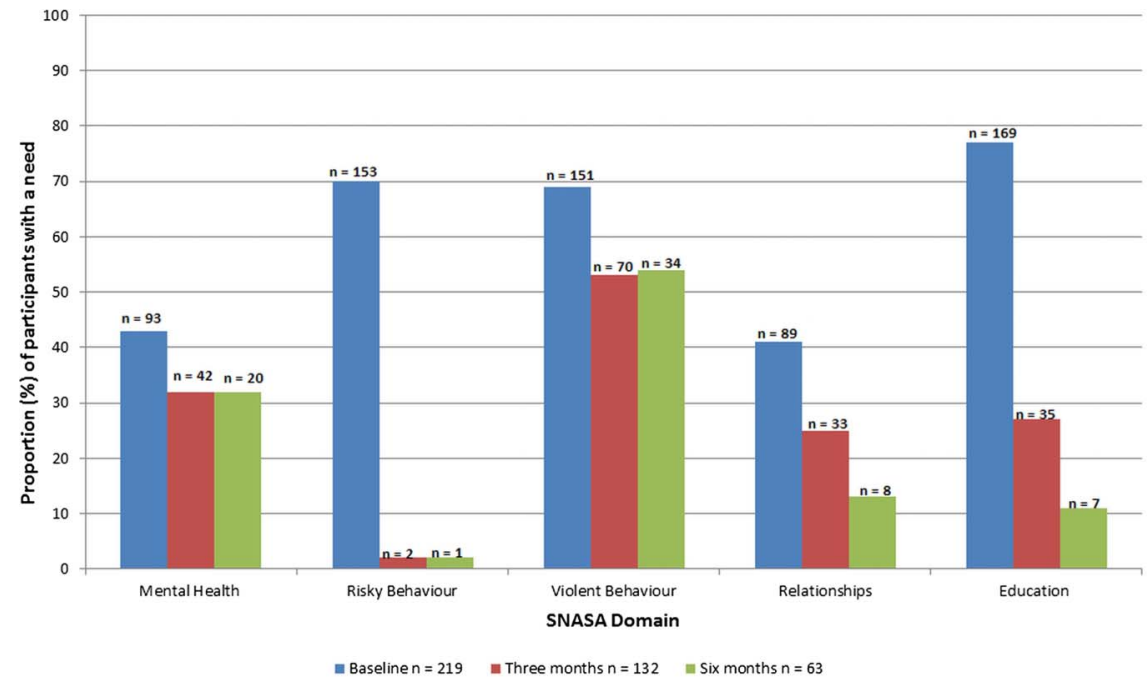


Table 2 Descriptive statistics and change over time analysis for the number of needs across Salford Needs Assessment Schedule for Adolescents domains

\begin{tabular}{|c|c|c|c|c|c|c|c|c|}
\hline & \multicolumn{2}{|l|}{ Baseline } & \multicolumn{2}{|l|}{3 months } & \multicolumn{2}{|l|}{6 months } & \multirow[b]{2}{*}{$\mathbf{F}$} & \multirow{2}{*}{$\begin{array}{l}\text { Significance } \\
\text { of } p \text { value }\end{array}$} \\
\hline & Mean & Median & Mean & Median & Mean & Median & & \\
\hline Mental health & 3.35 (3.17) & $3(1-5)$ & $2.03(2.24)$ & $1(0-3)$ & $1.65(1.80)$ & $1(0-3)$ & 26.26 & 0.001 \\
\hline Risky behaviour & $2.81(2.05)$ & $3(1-4)$ & $0.19(0.50)$ & $0(0-0)$ & $0.11(0.54)$ & $0(0-0)$ & 85.2 & 0.001 \\
\hline Violent behaviour & $2.65(2.04)$ & $3(1-4)$ & 2.02 (1.59) & $2(0-3)$ & $3.78(1.80)$ & $4(2-5)$ & 38.74 & 0.001 \\
\hline Relationships & $1.71(1.8)$ & $1(0-3)$ & $1.03(1.41)$ & $0(0-1)$ & 0.65 (1.09) & $0(0-1)$ & 20.9 & 0.001 \\
\hline Education & $2.83(1.71)$ & $2(2-4)$ & $1.44(1.9)$ & $1(0-2)$ & $0.87(1.2)$ & $1(0-1)$ & 42.89 & 0.001 \\
\hline Total needs & $4.40(2.60)$ & $4.5(2-6)$ & $2.02(2.02)$ & $1(1-3)$ & $1.45(1.47)$ & $1(0-2)$ & 64.96 & 0.001 \\
\hline
\end{tabular}

$\mathrm{N}=63 ;$ df 2,63.

Data presented within parentheses are SDs for mean data and quartiles for median data.

considered a case at baseline, but three became a case at 3 months but did not meet clinical criteria for 'caseness' at 6 months.

\section{DISCUSSION}

This study focused on the course of mental health and other needs and psychiatric morbidity during the first 6 months of imprisonment for adolescents. The findings

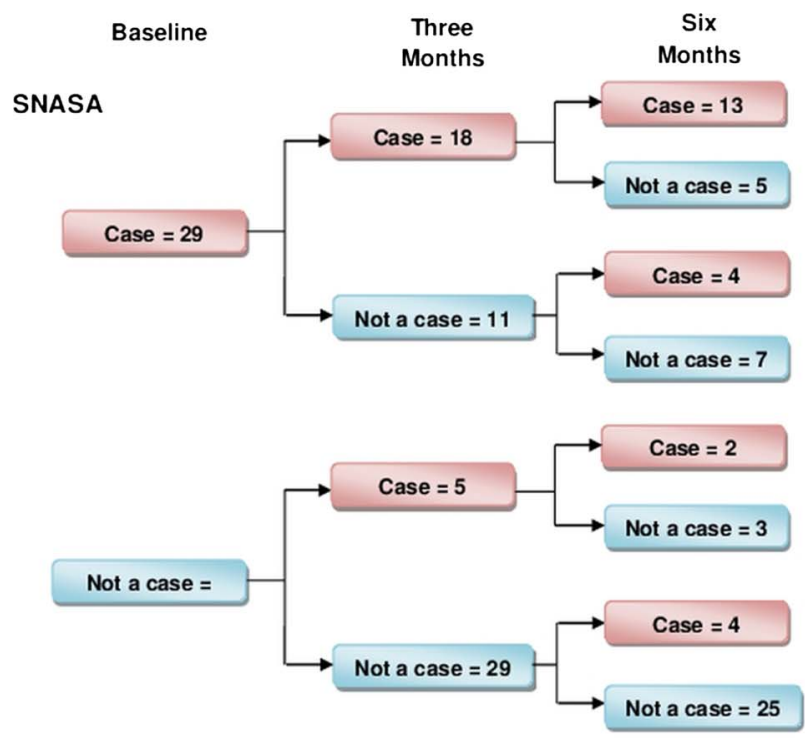

K-SADS

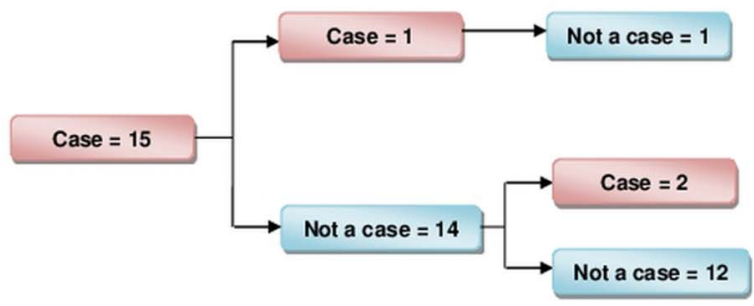

Not a case $=$

Case $=3$

Not a case $=3$

Figure 3 Change in clinical caseness on the Salford Needs Assessment Schedule for Adolescents and K-SADS. highlight the high levels of mental health and other needs of adolescents on reception into prison, but also show that mental health and other needs improve over the first 6 months of imprisonment.

There is only one previous UK study ${ }^{2}$ which is comparable to this research in terms of the measures used, but it focused on adolescents in secure care rather than on adolescents in prison. Secure care establishments have a higher staff to adolescent ratio, a smaller number of beds, a younger age group and a greater focus on providing a homely therapeutic environment compared with YOIs where the focus is on correctional rehabilitation. This study identified higher rates of alcohol (78\%) and substance $(73 \%)$ abuse problems at baseline using the K-SADS than the previous UK study, ${ }^{2}$ which identified rates of $48 \%$ and $69 \%$, respectively. This discrepancy may reflect the older age of this sample, but both studies point to high rates of substance abuse and alcohol problems that may be a significant criminogenic need in young offenders. Interestingly, we found lower rates of depression and anxiety on the K-SADS than reported previously, ${ }^{2}$ where $22 \%$ were reported to have major depression and $17 \%$ generalised anxiety disorder. Both studies noted that 'caseness' rates generally fell over time.

Looking at the baseline needs assessment data from the SNASA, we found particularly high levels of need in domains relating to risky and violent behaviour and education. Similar findings have been noted in previous studies. ${ }^{1} 22^{26}$ We found that $43 \%$ of our sample had mental health needs which are marginally higher than the $31 \%$ cited in a previous study in YOIs in the UK. ${ }^{26}$ Looking at the cohort who were able to complete all three assessment time points, there were significant reductions in the proportions having a need over time, in the domain of education, risky behaviour and relationships. While there appeared to be no significant reduction in the proportion having a mental health and violent behaviour need, there were significant reductions in symptom severity for depressed mood, self-harm, anxiety and psychotic symptoms.

More adolescents were identified as a case on the SNASA than on the K-SADS and there were more fluctuations in 'caseness' with the SNASA; this was to be expected, given that the SNASA is an assessment of 
needs rather than diagnosis. There were 13 young people who remained a case on the SNASA throughout the study. The reasons for remaining a case were complicated as a young person could be a case on multiple mental health domain items (depressed mood; deliberate self-harm; anxiety symptoms; PTSD problems; hallucinations, delusions, paranoid beliefs; hyperactivity) and symptomatology fluctuated. However, the main reason for remaining a case was fluctuations in ADHD symptoms, whereas symptom severity for anxiety, depression and self-harm for the majority of cases reduced. Of the nine adolescents who were not a case at baseline on the SNASA but 'caseness' emerged, again fluctuations in ADHD symptoms appeared to be the main reason. This is supported by the fact that we saw no significant differences in ADHD symptoms over time.

For 'caseness' on the K-SADS, the main reasons for those $(n=13)$ who were a case at baseline but not a case at follow-up were due to no longer meeting the criteria for PTSD. Of the emerging 'caseness' $(n=3)$, this included anxiety, depression and psychosis. On the surface, it would appear that there is little or no correlation between 'caseness' on the SNASA and the K-SADS; however, as highlighted above, differences in focus between the assessments, that is, needs versus diagnosis and that being a case on the SNASA mental health domain can be for multiple reasons, this masks any correlation. However, the three young people where K-SADS 'caseness' emerged were also identified as a case on the SNASA for the same reasons.

The identification of mental health problems as early as possible is important in young people who are entering a custodial environment as this may be an opportunity to address these needs in a structured setting for the first time. Research in adult establishments suggests that reception is not the most conducive environment to pick up on mental health issues as it tends to be busy and screening may not be conducted by mental health professionals. ${ }^{27}$ Given that previous studies ${ }^{4}$ suggest that nearly half of the adolescent males with mental health needs were missed on reception screening, a two-stage process may be required whereby new arrivals are reassessed in the weeks following the entry screen to ensure that key issues are highlighted and addressed. ${ }^{4}$

This study showed that mental health and other needs generally improved over time and the emergence of new needs or new cases was low. However, this study did not examine the interventions/programmes young people received; therefore, it remains unclear as to the reasons behind the improvement. For some young people leading chaotic lifestyles, merely being in a secure environment may reduce need by providing food, shelter and 'time out' from unhealthy lifestyles. The reductions seen in education, risky behaviour and relationships could therefore be the result of just being in a secure environment rather than receiving the appropriate treatment/ intervention, that is, limited access to drugs/alcohol, being away from family conflict.
The sample was made up of adolescent boys of whom the majority were White; while this does reflect the wider population of young people at the YOI included in this study, the results may not be generalisable to the wider secure estate, which includes adolescent girls and a larger proportion of ethnic minority groups. A UK study looking at the mental health needs of adolescents in prison and in the community found that, on the SNASA, female offenders had more needs than males, although this was not significantly different. However, the mental health domain did show a significant difference, in particular a higher proportion of females with needs in depression, self-harm and post-traumatic stress. They also found that White British adolescent offenders had more needs than those from Black and minority ethnic groups, although this was not significant. ${ }^{3}$ Given the higher rates of mental health need in females, and the known association between mental illness/self-harm and suicide in custody, ${ }^{13}{ }^{14}$ future research should focus on the course of mental illness in female adolescents. A further issue regarding the generalisability of the findings is that these adolescents were followed up for 6 months, and it is therefore not possible to know how they differed from adolescents who were imprisoned for longer, or whether the changes would be sustained over time. It would be important for future research studies to follow adolescents for a longer period, to look at differences between short-sentence and long-sentence prisoners and to include transition periods, that is, establishment transfers and discharge into the community. There was high attrition between baseline and 6-month follow-up as many were discharged (released or transferred), often with little warning. Despite the high attrition rates, there were no differences between those retained at follow-up versus those lost to demographic characteristics or rates of mental health need at baseline. This study was based on structured interviews with the young people, and we had little access to collateral information from parents or youth workers. Future studies should consider the inclusion of multiple sources of information on key need-related domains. ${ }^{28}$ There are many other factors that may have influenced the results such as individual coping styles, ${ }^{17}{ }^{18}$ access to formal/ informal support, prison programmes, employment, etc; therefore, future research should assess the treatment effects of the prison setting, different types of intervention/programmes, formal/informal support and service contacts on mental health and other needs.

These findings highlight the scale of the challenges faced by those providing healthcare to young people in detention and underline the need to address their health problems. Overall, this study suggests that prison may lead to a reduction in mental health and other needs, and that it can offer opportunities for interventions in high unmet need groups. These findings fit with previous studies in adult offenders in correctional facilities in the UK. ${ }^{21}{ }^{23}$ However, as each establishment will vary in relation to the facilities and environment they 
provide, the populations they serve and the interventions they provide, future research is needed to see if these findings are replicated in other prison settings and in different countries.

Acknowledgements We gratefully acknowledge the practical help and assistance given to the research team by prison discipline and healthcare staff and managers in facilitating our work. We also acknowledge all those young people who took part in the study.

Contributors $\mathrm{CL}$ and $\mathrm{MD}$ were involved in the conception and design of the study. CL and VB did the data collection. CL, KO and MD did the data analysis. $\mathrm{CL}, \mathrm{KO}$, JS and MD interpreted the data. CL, KO and MD drafted the manuscript, and all authors critically revised it for important intellectual context. All authors approved the final version to be published. MD is the guarantor.

Funding Financial support was by National Programme on Forensic Mental Health Research and Development (MRD 1286).

Competing interests None.

Ethics approval The study was approved by the South Staffordshire Research Ethic Committee.

Provenance and peer review Not commissioned; externally peer reviewed.

Data sharing statement No additional data are available.

\section{REFERENCES}

1. Lader D, Singleton N, Meltzer H. Psychiatric morbidity among young offenders in England and Wales. London: ONS, 2000.

2. Kroll L, Rothwell J, Bradley D, et al. Mental health needs of boys in secure care for serious or persistent offending: a prospective, longitudinal study. Lancet 2002;359:1975-9.

3. Chitsabesan P, Kroll L, Bailey S, et al. Mental health needs of young offenders in custody and the community. Br J Psychiatry 2006; 188:534-40.

4. Mitchell $P$, Shaw J. Factors affecting the recognition of mental health problems among adolescent offenders in custody. $J$ Forensic Psychiatr Psy 2011:22:381-94.

5. Teplin LA, Abram KM, McClelland GM, et al. Psychiatric disorders in youth in juvenile detention. Arch Gen Psychiat 2002;59:1133-43.

6. Vreugdenhil C, Doreleijers TAH, Vermeiren R, et al. Psychiatric disorders in a representative sample of incarcerated boys in the Netherlands. J Am Acad Child Psy 2004;43:97-104.

7. Fazel S, Doll H, Långström N. Mental disorders among adolescents in juvenile detention and correctional facilities: A systematic review and metaregression analysis of 25 surveys. J Am Acad Child Psy 2008;47:1010-20.

8. Colins O, Vermeiren R, Vreugdenil C, et al. Psychiatric disorders in detained male adolescents: a systematic literature review. Can $J$ Psychiat 2010;55:255-63.

9. Bailey S, Vermeiren R, Mitchell P. Mental health, risk and antisocial behaviour in young offenders: challenges and opportunities.
In: Blyth M, Solomon E, Baker K, eds. Young people and "Risk". Bristol: Policy Press, 2007:55-71.

10. National Health Committee. Review of research on the effects of imprisonment on the health of inmates and their families. Wellington, New Zealand: National Advisory Committee, 2007.

11. Harrington R. Depression, suicide and deliberate self harm in adolescence. Brit Med Bull 2001;57:47-60.

12. Ministry of Justice. Safety in custody statistics quarterly bulletin London: Ministry of Justice. http://www.justice.gov.uk/downloads/ statistics/prison-probation/safety-custody/safety-custody-janmarch-2012.pdf (accessed 1 Oct 2012).

13. Shaw J, Baker D, Hunt I, et al. Suicide by prisoners: National Clinical Survey. Br J Psychiatry 2004;184:263-7.

14. Shaw J, Appleby L, Baker D. Safer prisons: a national study of prison suicides $1999-2000$ by the National Confidential Inquiry into Suicides and Homicides by People with Mental Illness. Report for the Department of Health, Centre for Suicide Prevention: University of Manchester. 2003.

15. Singleton N, Meltzer H, Gatward R. Psychiatric morbidity among prisoners. London: ONS, 1998

16. Fazel S, Danesh J. Serious mental disorder in 23000 prisoners: a systematic review of 62 surveys. Lancet 2002;359:545-50.

17. Liebling A. Suicides in prisons. London: Routledge, 1992.

18. Liebling A. Prison suicide and prisoner Coping. In: Tonry M, Petersilia J, eds. Prisons, crime and justice: a review of research Chicago: University of Chicago Press, 1999:283-360.

19. Harrington R, Kerfoot M, Verduyn C. Developing needs led child and adolescent mental health services: issues and prospects. Eur Child Adoles Psy 1999;8:1-10.

20. Marshall T, Simpson S, Stevens A. Health care in prisons: a health care needs assessment. Birmingham: University of Birmingham, 2000.

21. Taylor $\mathrm{P}$, Walker J, Dunn $\mathrm{E}$, et al. Improving mental state in early imprisonment. Crim Behav Ment Health 2010;20:215-31.

22. Plugge E, Douglas N, Fitzpartick R. Changes in health-related quality of life following imprisonment in 92 women in England: a three month follow-up study. Int $J$ Equity Health 2011;10:21-8.

23. Hassan $\mathrm{H}$, Birmingham L, Harty MA, et al. Prospective cohort study of mental health during imprisonment. Br J Psychiatry 2011;198:37-42.

24. Kroll L, Woodham A, Rothwell J, et al. Reliability of the Salford needs assessment schedule for adolescents. Psychol Med 1999;29:891-902

25. Kaufman J, Birmaher B, Brent D, et al. Schedule for affective disorders and schizophrenia for school-aged children-present and lifetime (K-SADS-PL): initial reliability and validity data. J Am Acad Child Psy 1997;36:980-8.

26. Harrington R, Bailey S, Chitsabesan P, et al. Effectiveness of mental health provision for young offenders in custody and the community. London: Youth Justice Board, 2005.

27. Mitichison S, Rix KJB, Renvoize EB, et al. Recorded psychiatric morbidity in a large prison for male remanded and sentenced prisoners. Med Sci Law 1994;34:324-30.

28. Colins O, Vermeiren R, Schuyten G, et al. Informant agreement in the assessment of disruptive behavior disorders in detained minors in Belgium: a diagnosis-level and symptom-level examination. $J$ Clin Psychiat 2008;69:141-8. 